\title{
Economics of Plant Disease Outbreaks
}

\section{Khorshed Alam and John Rolfe}

I ncreasing trade liberalisation, globalisation and international transportation of people and commodities have increased the potential for disease incursion, both plant and animal, in countries like Australia. While a comparatively strict quarantine regime and geographic isolation provide substantial protection in Australia, disease incursions are not uncommon. In recent years, there have been several exotic disease outbreaks including wheat stripe rust, bacterial blight of cotton, sugar cane ratoon stunt, potato cyst nematodes, karnal bunt, grapevine leaf rust, papaya fruit fly, Newcastle disease in poultry flocks, and Ovine Johne's Disease (OJD) in sheep. Recent attention on the incursion of plant diseases followed the outbreak of black sigatoka, a banana leaf disease, in the Tully district of North Queensland in 2001, and citrus canker, a highly contagious bacterial disease for citrus fruits, in the Central Highlands region of Queensland in 2004.

An outbreak of any pest or disease, either plant or animal, has the potential to be widespread in countries like Australia, with subsequent economic, social and environmental impacts. At the same time, the trade liberalisation process is focused on avoiding quarantine being used as a trade barrier, where the risks of disease incursion are used to 'trump' any potential benefits of increased trade flows. There is a strong economic case for an efficient quarantine regime, with import, monitoring and surveillance procedures, and for appropriate eradication measures when disease outbreaks occur. Estimates of the economic cost of outbreaks, and the benefits of avoiding them, are needed to help weigh policy options about appropriate future prevention and response strategies.

A number of studies have been conducted on the entomology and epidemiology of introduced diseases (for example, Gottwald, Graham and Schubert, 2002). However, little research attention has been paid to the economics of such outbreaks (Hanold, 1996). In Australia, there has been work in recent years in the area of weed management which is analogous to the disease problem in terms of containment options and timing. A review is provided in the next section. Although public policy evaluation and administration of plant disease incursion issues are considered to be important, they remain understudied. The full extent of the costs of damages caused by pest and disease incursions has only recently received greater attention (Evans, 2003). There is only a limited number of studies attempting to quantify the economic losses of plant disease outbreaks and the desirability of appropriate response strategies.

To estimate the economic cost of an outbreak, proper identification of losses incurred and their quantification are important. Costs of an outbreak can be

Khorshed Alam is Lecturer in the Department of Economics and Resources Management, Faculty of Business, University of Southern Queensland. John Rolfe is Associate Professor in the Faculty of Business and Informatics, Central Queensland University 
generated from three different sources: (i) surveillance, control and eradication; (ii) losses of production, income and employment and its effects on ancillary industries; and (iii) loss of trade access. In addition to these costs, there might be non-market impacts and costs to consider. For example, impacts on biodiversity will not be reflected in market transactions, and would require specialised nonmarket valuation techniques in the assessment stage.

At a policy-making level, there is often interest in showing that the benefits of control measures outweigh the costs. There may also be interest in evaluating what the net benefits of different control measures should be. Techniques of economic analysis can be used to estimate the economic cost of an outbreak. In this paper, an economic analysis of the government response to the 2004 citrus canker outbreak in Queensland is provided. The analysis is focused on two key issues. The first is to confirm whether control measures were appropriate, while the second is to identify what level of control would have been most effective. An additional consideration for this paper is the economic issues involved in potential compensation for growers affected by the outbreak.

The next two sections of the paper describe the importance of economic analysis and provide a review of the techniques employed to estimate the economic impact of disease outbreaks. The subsequent section discusses the sequence of events of the citrus canker outbreaks in Queensland. Then follows a section, which provides a comparative analysis of the national response strategy to the citrus canker against the alternative Pressler Plan. The penultimate section presents an economic analysis of optimising the response strategy on eradication and control measures. Conclusions are presented in the final section.

\section{The Importance of Economics of Disease Incursion}

An economic framework can be used to explain why a government response is typically needed for the prevention and control measures in a disease infected industry. Relying on control by private firms is usually ineffective because any incursion of a disease has an external effect on market activities. Costs are not borne solely by the source of the incursion, but spillover (intentionally or unintentionally) into other areas, without affected parties being able to exact a compensation for the damage incurred. Therefore, many of the impacts of a disease outbreak are spillovers in the sense that the market mechanism is unable to transmit back the true cost of a plant disease outbreak to an infected source.

For instance, neither commercial nor backyard scale citrus growers have adequate incentives for voluntary eradication. Citrus canker containment and eradication actions demonstrate many of the characteristics of a public good. Disease-free industry status has aspects of non-rivalry in consumption (that is, one orchard's ability to enjoy disease-free status does not deprive others) and nonexclusion in provision (that is, it is difficult to exclude growers from enjoying this status). Growers often face powerful incentives not to report disease incursions to the authority responsible for monitoring and surveillance, because the removal of trees can impose major financial losses to orchards. The first infected farm in 
Emerald sought an injunction from the court to stop trees being cut and destroyed after the original outbreak in June 2004. In Florida, a legal battle continued for some time to determine whether the regulatory authority should have the right to trespass the property to test for canker infestation and to remove diseased trees (Brown, 2001; Gottwald, Graham and Schubert 2002). However, failure to control the disease would result in negative external effects on other growers as citrus canker would spread to other residences and commercial orchards. Therefore, the costs to other growers are not usually internalised into private decisions, but are of concern to public regulatory agencies and other stakeholders.

Furthermore, prevention of disease outbreaks requires extensive monitoring and surveillance both by the regulatory authority and individual grower. On the part of the growers, this imposes additional costs on them. While there may be market incentives to maintain a disease-free status, there will often be some incentives for free-riding at the individual grower level. This can occur if growers fail to monitor or eradicate in an effort to reduce costs. Therefore, there is potential for market failure at both the prevention and eradication stages and thus a role for government intervention at both levels.

When a disease outbreak occurs, a public policy framework in the form of a benefit-cost test is usually employed to justify control and eradication measures. This often involves a mixture of public and private costs being incurred to avoid more wide-spread private costs if disease became established.

Governments have a range of policy mechanisms to use when addressing disease outbreaks. These include the use of public information and suasion methods to encourage appropriate action and voluntary compliance. Incentives for growers to voluntarily report, control and monitor outbreaks can also be enhanced with the use of financial instruments. Regulatory and control measures are an alternative or extensions to voluntary mechanisms, and have advantages in terms of response certainty and timelines. However, the use of regulatory approaches to control may generate offsetting flow-on effects if they reduce growers' incentives to report and monitor outbreaks. Therefore, there is a number of economic issues raised in disease control measures. From the perspective of society, it is important to determine whether the control and eradication measures are worth the cost of implementation. An economic analysis is considered appropriate for this purpose.

\section{A Review of Economic Analysis Approaches to Disease Outbreaks}

Broadly speaking, two approaches are used to estimate the economic cost of an incursion, namely impact modelling and economic surplus analysis. Impact modelling can take the form of an input-output (I-O) model or a computable general equilibrium (CGE) model. An I-O model captures the supply and demand of goods and services in an economy (within an industry, region and economywide) in a particular period, as well as the interdependencies among the industries and associated primary factors of production (Elliston, Hinde and Yainshet, 2005). By tracing these linkages between sectors, the model estimates the effect of an impact on the region's output, employment, income and imports, often expressed 
in the form of multipliers. An I-O model can be used to capture the direct effects (output, income and employment) of a change in demand or supply as well as the indirect or flow-on impacts on its ancillary sectors (suppliers of inputs and process industries). It can also be used to measure the demand substitution effects, that is, consumers' shift of consumption to substitute commodities.

Computable general equilibrium (CGE) models are constructed on the same data as the input-output models. A CGE model can provide information about the magnitude and sources of economic losses and the appropriate design of mitigation strategy (for example, eradication vs containment). Both I-O and CGE models are able to capture the economy-wide impacts and inter-industry linkages, however, a CGE model has greater flexibility in terms of underlying assumptions and generates less biased estimates compared to I-O model (Adamowicz et al., 2000). Furthermore, CGE models have advantages over I-O models in that they can be used to estimate not only the economic impacts but also the distributional impacts (White and Patriquin, 2003). However, I-O models have advantages in that they help to understand the social and political impacts.

Elliston, Hinde and Yainshet (2005) assessed the economic impacts of an incursion of karnal bunt in a hypothetical situation in South-eastern Queensland using an input-output model. This study, however, failed to capture the changes in economic surplus. The I-O model estimated the changes in output and employment, not the economic welfare, making it difficult to assess the overall gains or losses to society. Wittwer, McKirdy and Wilson (2005) estimate both the micro and macroeconomic effects of a hypothetical incursion of karnal bunt in wheat in the wheat belt of Western Australia using a CGE model. The analysis showed that quarantine restrictions in foreign markets dominated economic losses of the incursion of exotic plant diseases or pests.

Using the MONASH Multiregional Forecasting Model (MMRF), a version of CGE model, Dent et al (2002) estimated the likely impact of a foot-and-mouth disease (FMD) outbreak in Queensland and other regional economies. The study estimated the direct impact on 'at risk' industries and associated products as well as the flow-on effects to other industries and the economy as a whole. The study found that an outbreak of FMD would impact not only the livestock farming and meat processing industries, but also other sectors in the economy (for example, tourism). The impact of the hypothetical FMD outbreak in Queensland (a major beef cattle state) was proportionately more severe than the national impact. In Queensland, the real GDP was projected to be \$2,340 million below the base case, while employment was projected to be 33,900 jobs below the base case in Year 7 alone. These losses are far greater than the projected Year 7 losses in the national livestock farming industry (\$700 million and 1900 jobs) and the national livestock product (mainly meat processing) industry (\$200 million and 5100 jobs). Although the estimated total control cost of FMD outbreak (\$500 million) appears significant, however, it is considered to be minor when compared to the potential loss of the national economy.

Economic surplus analysis is used to estimate the net gains and losses of different impacts to society, and is normally preferred to impact modelling as a 
more appropriate measure of welfare changes. Within this framework, a partial equilibrium approach can be used to estimate the net losses due to an incursion, and the distribution of such losses between producers and consumers, expressed as changes in producer and consumer surplus. The economic surplus approach can be performed at a case study level, where the net surplus can be estimated with the application of cost-benefit analysis (CBA).

With this method it is possible to demonstrate how a disease outbreak can reduce the welfare gains which might otherwise have been obtained from the industry in the absence of an incursion. The economic surplus method has been used to estimate the cost of weeds in annual winter cropping system in Australia (Jones et al., 2000), and to measure the benefits of the virus prevention program in deciduous fruit trees in the US (Cembali et al, 2003).

Jones et al (2000) estimated the economic costs of weeds and their distribution in Australian annual winter cropping systems using the economic surplus model. The loss of economic surplus due to weed infestations and weed control expenditure was estimated at $\$ 1,133$ million in 1999. The distribution of total economic surplus suggested that producers appropriate the bulk of the economic welfare gained from the control measures (about 95 per cent), while consumers gained to a small extent (about 5 per cent) from the reduced market prices resulting from increased production due to weed control. The economic surplus approach measured both direct and indirect costs, but non-monetary impacts were not considered.

Cembali et al (2003) estimated net economic benefits of a virus prevention program for apples, sweet cherries and clingstone peaches in the United States at the nursery, grower and consumer levels as changes in consumer and producer surpluses. Empirical estimates of the expected yield losses at both nursery and grower levels were made using the method of avoided losses. Avoided costs were used to estimate program benefits in three economic sectors: nurseries (avoided change in producer surplus), producers (avoided change in consumer and producer surpluses), and consumers (avoided change in consumer surplus). The empirical estimates suggested that the total benefits for all three sectors were approximately $\$ 227.4$ million a year, or more than 420 times the cost of the program.

Paarlberg, Lee and Seitzinger (2003) measured the welfare effects of an FMD outbreak in the United States using the economic surplus method. They decomposed the effect by groups, including livestock producers with animals quarantined and slaughtered and producers not quarantined, using lost sales and producer surplus measures respectively. Similarly, consumer surplus was decomposed for consumers with and without changes of consumption behaviour (that is, whether or not consuming beef considering potential human health effects from an outbreak). The researchers argued that decomposition of aggregate welfare (consumer or producer surpluses) for different groups could provide more accurate estimates of changes for the policy-decision, and help to design compensation provisions.

Rabbits impose economic costs on wool producers, governments, communities and the environment. Vere, Jones and Saunders (2004) provided an 
economic analysis of rabbit control measures in the Australian temperate pastures through integrating estimates of the costs of rabbits in the pasture systems and the benefits of implementing control practices from the introduction of rabbit haemorrhagic disease (RHD). The approach taken was to (i) determine the changes in livestock production at the farm level due to supply shifts; (ii) simulate these changes within a livestock industry model (that is, quantities, prices and elasticities); and (iii) calculate the resulting economic welfare changes (that is, net benefits) and the relative benefits and costs of improved rabbit control over time. The study showed that controlling rabbits in temperate pastures by RHD had the potential to generate substantial long-term economic benefits - the benefit-cost ratios were between 2.9:1 and 16.2:1 for a 25 per cent rabbit reduction and for a 50 per cent reduction the ratios were between 5.9:1 and 32.4:1.

Zansler, Spreen and Muraro (2005) employed cost-benefit analysis to determine whether the citrus canker eradication program in Florida could be a useful policy tool in combating the economic ramifications associated with the outbreak using the predicted values of the benefits and the costs associated with the intervention. The results of the benefit-cost analysis suggested that benefits of the program outweighed the costs.

This review of current literatures on plant or pest disease incursions demonstrates that both economic surplus and CBA cannot sufficiently capture the indirect or flow-on effects of an impact. On the other hand, I-O or CGE model cannot take into account non-market impacts or estimate net welfare change. Both approaches have their strengths and limitations. In this paper, the approaches of economic surplus and CBA are used to indicate the economic efficiency of citrus canker outbreak control and eradication strategies in Queensland.

\section{Case of Citrus Canker Outbreak in Central Highlands of Queensland}

The citrus industry in Australia makes a substantial contribution to the national economy and the generation of employment. Major citrus fruits in Australia include oranges (navel and valencia), mandarins, lemons, limes and grapefruit. In 2002-03, citrus production in Australia consisted of 81 per cent oranges (valencia 45 per cent and navel 36 per cent), 14 per cent mandarin, 4 per cent lemon and lime and 1 per cent grapefruit. The industry produces around 830 thousand tones of fruit per year with a gross value of production of $\$ 426 \mathrm{~m}$ in 2002-03. Citrus is one of the major horticultural exports in Australia, generating around $\$ 160 \mathrm{~m}$ of annual export income and contributing $\$ 250 \mathrm{~m}$ directly to value-added products (ACG, 2001). Exports accounted for around 20.6 per cent of total production in 2002-03 (PHA, 2004). There was a record export of citrus by value of $\$ 201 \mathrm{~m}$ in 2002-03 (ACG, 2004). The focus of both the production and export of citrus is on fresh fruits and processed juice products. The citrus industry is Australia's largest fresh fruit exporting industry.

Commercial citrus production in Queensland is localised in the Central Burnett and Central Highland regions; out of 3,000 growers (cultivating 32,000 hectares of land) in Australia, about 300 are located in these regions (ACG, 2001). 
Seventy five per cent of Queensland's citrus is produced in the GayndahMundubbera (Central Burnett) region and the Emerald Shire (Central Highland region); the remainder is grown in Bundaberg, Capricorn Coast Region, Wide Bay, Mareeba (Far North), Sunshine Coast and some other small patches of land in the State. The citrus industry generates about $\$ 80 \mathrm{~m}$ annually to the Queensland economy and supports several thousand jobs, particularly for seasonal workers. The majority of fruit is transported to southern markets and some is exported.

Citrus canker is a highly contagious disease that causes defoliation and dieback, severely blemished fruit, weakens trees and eventually reduces production, although it is not harmful to humans. The disease was first discovered in Queensland in early June 2004 on a 1,200 hectare (ha) orchard with 220,000 citrus trees (Evergreen Farm) near Emerald in Central Highlands region. Immediately after the detection of the incursion, a Pest Quarantine Area (PQA) was declared for the Shires of Bauhinia, Emerald and Peak Downs, surrounding the infested orchard. As well, an interstate ban on the movement of Rutacae (the plant family to which citrus belongs) fruits was imposed. The trade ban was also imposed on the Gayndah/Mundubbera region due to its proximity to Emerald citrus growing region and the possibility that disease might spread through the movement of plant material and seasonal workers. Growers were restricted from trading fruit or plant material within Queensland or interstate. The interstate trade of citrus for fruits grown outside of the Central Highlands and the Gayndah/ Mundubbera region resumed on the 22 July, while for citrus growers in the Gayndah/Mundubbera region trade resumed on the 13 January 2005. Furthermore, all Australian citrus growers were required to undergo stricter quarantine checks before exporting fruit to New Zealand pending quarantine surveys to establish state, area or property freedom from citrus canker.

While the European Union stopped importing citrus from Australia until a canker-free status was established for the whole country, export to other markets, particularly canker infected markets in Asia, did not face any restriction.

Citrus canker was widespread on the first affected property. Under the National Citrus Industry Biosecurity Plan (NCIBC) introduced in April 2004, a 'cookie cutter' approach involving destruction of trees within 600 metres of an infected area is considered to be effective control. By late 2004, all the 220,000 trees on the first affected property were taken out with successive 'cookie cuts'.

A second incursion within the Emerald irrigation area was reported on October 5, 2004 on Queensland's largest citrus orchard, known as 2PH Farms, having 326,000 fruit trees. This orchard is only $7 \mathrm{~km}$ away from the first infested farm and subsequent DNA testing confirmed that this latter outbreak was linked to the first one. By July 2005, three orchards in Emerald were affected with six outbreaks and over half a million citrus trees had been destroyed.

Some of the revenue and expenditure impacts on the Emerald region can be estimated as follows:

- $\quad$ annual loss of revenue to growers from tree removal as of July 2005 was $\$ 21.3 \mathrm{~m} /$ year (500,000 trees at $\$ 42.6$ estimated annual production/tree); 
- annual loss of revenue to growers if all citrus trees removed from Emerald would be $\$ 31.95 \mathrm{~m} /$ year ( 750,000 trees at $\$ 42.6 /$ tree);

- $\quad$ surveillance and control cost allocation by government was $\$ 13 \mathrm{~m}$ (perhaps more than 50 per cent spent in the Emerald region); and

- $\quad$ several hundred full-time jobs and more than one thousand part-time jobs are anticipated to have been lost.

With disease outbreak in livestock, compensation is automatically paid. However, this was not the case with a citrus canker outbreak as no cost sharing deed for emergency pest management was in place during the Emerald incursion.

The Queensland citrus industry has been affected by the loss (short to midterm) of some overseas markets and if domestic consumers reduce demands for citrus fruits. Such losses will flow the temporary ban on interstate trade. Losses may also extend to domestic markets, especially through to other parts of the economy, such as transport, wholesale and retail sectors. On the eradication side, the citrus canker outbreak has generated higher control costs for private industry, as well as considerable costs for eradication and control by the regulatory authorities. This raises questions as to the impact on Queensland's citrus industry and society as a whole, and whether public expenditure on control and eradication was an efficient use of funds.

\section{The Pressler and the National Citrus Industry Biosecurity Plans}

A debate has taken place about the most efficient way to perform control and eradication measures in the region. Under the NCIBP, all trees within 600 meters of an infection are removed, and then monitoring continues. After the first disease detection on the second farm, the owner, John Pressler, put forward a proposal to destroy all the citrus plants in Central Highlands region around Emerald. The core of this proposal, referred to in the media as the Pressler Plan, was for growers to destroy all remaining trees with financial support from the Government. This would involve funding for the growers of $\$ 16 \mathrm{~m}$ ( $\$ 50$ payment for destruction per tree). This would reduce any chance of canker spreading and then allow the area to re-plant after two years. The rationale behind the Pressler Plan was that if the current eradication program failed to eliminate the disease completely from the region, on-going outbreaks would lock growers out of markets for long periods of time. If implemented, the Pressler Plan would provide growers with certainty about their re-establishment and market access. After the destruction, the growers will be required to fallow the land for the next two years, replant and wait for the new trees to bear their first crop. An orchard will return to its production in five to six years time.

Considering Emerald's isolation from the other growing regions in the State and the high probability of returning to production, this proposal received support from the growers in the region. However, the government rejected the Pressler Plan, preferring to continue with the response strategy under the nationally approved response plan. It was argued that the response plan would be effective 
and that the risk of continued outbreaks was very low. Subsequent to the rejection of the Pressler Plan, two further outbreaks were discovered at the 2PH farm, and another outbreak discovered at a third farm in the region. Finally, the National Management Group in June 2005 supported the removal of all citrus trees, including domestic and wild native trees in the Emerald PQA, but without any provision of compensation or voluntary agreement with growers.

The effectiveness of the NCIBP in eradicating the disease is a key issue. Citrus canker is still endemic in Florida (USA) despite applying the 'cookie cutter' approach for more than a decade in response to citrus canker outbreaks. Grower and industry concern at Emerald was that under the 'cookie cutter' approach all citrus trees in the region might eventually face destruction as further infections were detected.

\section{Evaluating the Response Strategies}

An economic analysis of quarantine and control measures can take two basic forms. The first form of analysis is to identify the net benefits of control measures. The net costs of control can be estimated as the changes in producer and consumer surpluses, plus the public expenditure committed to the program. The benefits of the control measure include the avoidance of further public expenditure on controls, the protection of producer and consumer surpluses, and the avoidance of public expenditure on industry and regional community support. Given the size of the citrus industry in Australia, the potential public expenditure involved in controlling a major outbreak, and the vulnerability of many regional communities to a downturn in the citrus industry, it is likely that there are major net benefits associated with controlling the disease.

The averted cost framework can be used to evaluate this issue. For the Pressler Plan to have provided net benefits, the estimated \$16m cost (destruction cost of about 326,000 remaining trees in the Emerald PQA) should have been lower than the cost of potential impacts multiplied by the likelihood of outbreaks occurring. The total cost of a major outbreak is difficult to estimate, but some broad assumptions can be used to help with the analysis. If a major outbreak occurred across the citrus industry, markets would close and there would be substantial control costs. If producer surplus is estimated at 10 per cent of current industry production ( $\$ 426 \mathrm{~m} /$ year), and production is affected for at least five years to return to production, the discounted present value of producer surplus, at an 8 per cent discount rate, may be estimated at $\$ 170 \mathrm{~m}$. To this should be added potential control costs, as well as additional welfare payments associated with support for unemployment and impacts on regional communities. Given that a potential control cost of $\$ 13 \mathrm{~m}$ has been allocated by the government for the Emerald outbreaks, a potential control cost of $\$ 40 \mathrm{~m}$ may be appropriate for a wider national outbreak. If the citrus industry is closed down in Australia for 5 years, over $\$ 2$ billion in direct revenue would be taken out of mainly rural communities. It is not unrealistic to expect that the public support would be 
needed to account for the total impact. At a 10 per cent support level, total costs (loss of producer surplus) would be $\$ 200 \mathrm{~m}$.

To summarise, an eradication measure for citrus canker has net benefits because it averts three main types of potential costs in the Australian situation:

- $\quad$ losses in producer surplus (effectively the present value of industry profits in Australia);

- avoided expenditure on control measures for major outbreaks; and

- $\quad$ avoided expenditure on industry reconstruction and community support.

Using the rough estimates provided above, the economic benefits of averting a national outbreak of citrus canker are $\$ 410 \mathrm{~m}$, while the public cost of eradication was estimated to be $\$ 13 \mathrm{~m}$. There are clear benefits in pursuing eradication measures.

The second form of analysis is to identify the level of control that yields the highest net benefits. An example of this approach can be demonstrated by evaluating the net benefits of the Pressler Plan compared to the NCIBP. Here, the difference in the costs of control measures between the plans is compared. Both the tangible and intangible costs and benefits between the Pressler Plan and current NCIBP are summarised in Table 1.

Table 1: Additional Benefits and Costs of the Pressler Plan over the National Citrus Biosecurity Plan

\begin{tabular}{|c|c|}
\hline Benefit & Cost \\
\hline $\begin{array}{l}\text { Reduced chance of further outbreaks and } \\
\text { hence certainty of returning to farming by }\end{array}$ & $\begin{array}{l}\text { Payments to growers for destruction of } \\
\text { trees ( } \$ 50 / \text { tree) }\end{array}$ \\
\hline growers & Replacement costs to replant trees \\
\hline $\begin{array}{l}\text { Reduced inspection costs by government } \\
\text { over longer term }\end{array}$ & $\begin{array}{l}\text { Loss of production \& sales for } 5 \text { years } \\
\text { (net with other crop return) }\end{array}$ \\
\hline $\begin{array}{l}\text { Increased certainty about eradication and } \\
\text { hence avoided loss of domestic and }\end{array}$ & $\begin{array}{l}\text { Precedence set for different quarantine } \\
\text { control plan }\end{array}$ \\
\hline $\begin{array}{l}\text { international (especially USA and EU) } \\
\text { markets }\end{array}$ & $\begin{array}{l}\text { Potential impacts on other industries (e.g. } \\
\text { grapes and melons) if growers diversify }\end{array}$ \\
\hline Avoided public costs on control of any & into other crops \\
\hline $\begin{array}{l}\text { further outbreaks } \\
\text { Private benefits of replanting with better } \\
\text { fruit stock }\end{array}$ & $\begin{array}{l}\text { Impacts on households of removing all } \\
\text { domestic citrus trees }\end{array}$ \\
\hline
\end{tabular}

The key issue is whether the reduced risk of eradication represented by the Pressler Plan would have generated sufficient benefits to justify the increased costs. Jetter, Civerolo and Sumner (2003) reporting for citrus canker infestations in California, estimated an eradication boundary of 1,900 feet (579 meters) resulted in a 95 per cent chance of eradication. The probability of eradication increased to 99 per cent if the boundary was increased to 3,000 feet (914 meters). 
There have been multiple outbreaks of citrus canker in the United States as the 1,900 feet 'cookie-cutter' approach to eradication has not been fully successful in controlling the disease, indicating that a 95 per cent probability may be overestimated. If the probability of a subsequent outbreak under the NCIBP is only 5 per cent, then the probability of several successive outbreaks is extremely low. Given that the latter has occurred at Emerald, it appears that the real probability of an outbreak is higher than 5 per cent.

If the current NCIBP is assumed to have a 95 per cent chance of eradication and the Pressler Plan assumed to have a 100 per cent chance, the key issue is whether a 5 per cent increase in the probability of eradication would have been justified in comparison to the change in net costs. The key additional cost involved in the Pressler Plan was $\$ 16 \mathrm{~m}$ to be paid to growers as partial compensation for the removal of the remaining trees.

The total cost of a major national outbreak has been assessed at $\$ 410 \mathrm{~m}$. This amount should then be multiplied by the potential risk of occurrence to determine the appropriate avoided cost to consider. At 10 per cent, 5 per cent and 2.5 per cent levels for risk of occurrence, these expected benefits are $\$ 41 \mathrm{~m}, \$ 20.5 \mathrm{~m}$ and $\$ 10.25 \mathrm{~m}$ respectively. Comparing this to the expected cost of $\$ 16 \mathrm{~m}$ suggests that the Pressler Plan would have delivered net benefits at the 10 per cent and 5 per cent risk levels, but not at the 2.5 per cent risk level. This indicates that the Pressler Plan was justified on an economic basis when the mitigation strategy has only a 95 per cent probability of eradication.

With the 'cookie cutter' approach, the risk of occurrence still remains. Experience in Florida showed that as the boundary of the eradication zone increased, the eradication costs also increased. Spreen and Zansler (2003) estimated the economic costs to Florida citrus growers in two scenarios: production costs associated with the eradication of citrus trees due to a canker infestation, and production costs associated with living with citrus canker. A hypothetical canker-free orchard was modelled for the comparison. Results indicated that the estimated economic loss to citrus growers in an endemic citrus canker situation exceeded the estimated economic loss to citrus growers under eradication. Studies in Florida also showed that 90 per cent of the citrus canker infections occurred within the1,200 feet buffer, but wind-borne spread could carry viable bacteria as far as 3,900 feet (USDA, 1999). Using Argentina as an example for a Florida citrus canker control program, Muraro, Roka and Spreen (2000) concluded that compared to 'living with canker', eradication was a worthy choice if the disease was identified early and the action was taken swiftly and decisively.

\section{Conclusion}

The threat to biosecurity from exotic plant pests and diseases is a major one for Australia, where a single incursion can generate large commercial, economic and social costs. Evidence of this comes from the recent outbreak of citrus canker in orchards at Emerald in Central Queensland. It is not only local growers who bear costs, as a range of other stakeholders (including taxpayers) are potentially 
affected. To design an appropriate response strategy, it is important to be able to analyse the impacts and costs in economic terms, and provide a comparison of the potential benefits and costs of different response strategies.

There is controversy concerning the efficacy and economic efficiency of the appropriate response mechanisms to citrus canker outbreaks in Emerald. The public funding allocation for eradication is estimated at $\$ 13 \mathrm{~m}$; there will also be a range of private costs involved in control and eradication. The averted costs of the eradication measures are very large, indicating there are substantial net benefits associated with complete destruction of citrus trees in the region.

Questions can be raised about the effectiveness of the NCIBP in two main areas. The first is that plant growers are not compensated for tree destruction in disease control measures. This contrasts to the compensation provided to livestock producers for animals destroyed to control disease (for example, brucellosis outbreaks in the cattle industry). The lack of compensation measures means that growers may face large individual incentives not to report disease outbreaks. Some form of compensation appears to be justified on equity and efficiency grounds, and given the distribution of the benefits of control measures, should be funded by both government and industry.

The second issue about the effectiveness of the NCIBP is that the likelihood of success was overestimated. A basic economic analysis has shown that the Pressler Plan would have been a more efficient control measure if the probability of the 'cookie cutter' approach being successful was 95 per cent or lower. Given that this approach failed, not once, but several times, to control the disease at Emerald, the probability of success of the 'cookie cutter' approach would appear to be much lower than 95 per cent. The economic analysis in this paper indicates that the government should have accepted the Pressler Plan.

These results suggest that the NCIBP is flawed. The control of further disease outbreaks is likely to be enhanced: (i) if there are better incentives for individual growers to comply with the plan; (ii) if more accurate assessment of the probability of success of the 'cookie cutter' approach is provided; and (iii) if more widespread control measures like the Pressler Plan can be considered as the most cost-effective control strategies from the perspective of society. The use of economic analysis to identify the potential benefits and costs of different levels and types of control measures is recommended as part of a review of the control and eradication strategy. This analysis demonstrated that the total net benefit of a complete destruction of the Emerald citrus trees outweigh the costs to control and industry losses under the scenario of at least 95 per cent probability of eradication. To strengthen on-farm biosecurity measures, growers infected with canker can be compensated to offset the loss with reporting the disease and being placed under quarantine restrictions.

Some of the issues of disease outbreak from an economic perspective have been highlighted in this paper. An economic analysis can contribute towards understanding the problems of disease incursion through assessing the economic cost of the incursion and designing the optimal control and eradication strategies. There are private and social dimensions to the control and eradication program 
which need to be economically evaluated to justify investment in response strategies. Any response strategy to reduce the economic losses should be based on reliable estimates of control costs and the economic returns to implementing control practices. From an economic perspective, optimising a policy-decision in terms of adopting a response strategy needs to be based on economic principles in that the benefits of the mitigation strategy should outweigh costs.

\section{References}

Adamowicz, W., J. Alavalapati, G. Armstrong, M. Haener, J. Jabs and M. Patriquin. (2000), 'Assessing the Economic Impacts of Natural Disturbance Forest Management', Sustainable Forest Management Network Project Report 2000-30, University of Alberta.

Australian Citrus Growers Incorporated (2001), 'Enhancing the Performance of the Citrus Growing Industry', Submission to the Productivity Commission Inquiry into Citrus Industry, Canberra.

Australian Citrus Growers Incorporated (2004), 'Australian Citrus Growers 56th Annual Report 2004’, Australian Citrus Growers Incorporated, Victoria.

Brown, K. (2001), 'Florida Fights to Stop Citrus Canker’, Science 292(5525):2275-6.

Cembali, T., R. Folwell, P. Wandschneider, K. Eastwell and W. Howell (2003), 'Economic Implications of a Virus Prevention Program in Deciduous Tree Fruits in the US’, Crop Protection 22(10):1149-56.

Dent, S., J. Switala, P. Adams and M. O’Sullivan (2002), 'Foot-and-Mouth Disease Outbreak: Modelling Economic Implications for Queensland and Australia', Australasian Journal of Regional Studies 8(3):303-25.

Elliston, L., R. Hinde and A. Yainshet (2005), 'Plant Disease Incursion Management', Lecture Notes in Computer Science 3415(Jan):225-235.

Evans, E. (2003), ‘Economic Dimensions of Invasive Species’, Choices Second Quarter:510.

Gottwald, T., J. Graham and T. Schubert (2002), 'Citrus Canker: The Pathogen and its Impact', Plant Health Progress, Online doi:10.1094/PHP-2002-0812-01-RV, http://www.plantmanagementnetwork.org/pub/php/review/citruscanker/.

Hanold, D. (1996), 'Recent Incursions of Plant Pathogens 1970-1995', A Report to the Australian Quarantine Committee 1996, http://www.australasianplantpathologysociety. org.au/Member\%20Services/Incursions/Hanold_Inc_PlPath_96_AS.htm, accessed 20 September 2004.

Jetter, K., E. Civerolo and D. Sumner (2003), 'Ex-ante Economics of Exotic Disease Policy: Citrus Canker in California', pp. 121-150 in D. Sumner (ed), Exotic Pests and Diseases: Biology and Economics for Biosecurity, Blackwell Publisher Professional.

Jones, R., Y. Alemseged, R. Medd and D. Vere (2000), 'The Distribution, Density and Economic Impact of Weeds in the Australian Annual Winter Cropping System', CRC for 
Weed Management Systems Technical Series No. 4, CRC for Australian Weed Management, University of Adelaide.

Muraro, R., F. Roka, and T. Spreen (2000), ‘An Overview of Argentina’s Citrus Canker Control Program with Allocable Costs for a Similar Program in Florida', Proceedings of the International Citrus Canker Research Workshop, June 20-22, Ft. Pierce, Florida.

Paarlberg, P., J. Lee and A. Seitzinger (2003), 'Measuring Welfare Impacts of an FMD Outbreak in the United States', Journal of Agricultural and Applied Economics 35(1):53-65.

Plant Health Australia (PHA) (2004), 'National Citrus Industry Biosecurity Plan’, Plant Health Australia, Canberra.

Spreen, T. and M. Zansler (2003), 'The Costs and Value Loss Associated with Florida Groves Exposed to Citrus Canker', Proceedings of Florida State Horticulture Society 116:289-94.

United States Department of Agriculture (1999), 'Citrus Canker Eradication Program: Environmental Assessment 1999’, Animal and Plant Health Inspection Service, Riverdale, MD.

Vere, D., R. Jones and G. Saunders (2004), 'The Economic Benefits of Rabbit Control in Australian Temperate Pastures by the Introduction of Rabbit Haemorrhagic Disease', Agricultural Economics 30(2):143-55.

White, B. and M. Patriquin (2003), 'A Regional Economic Impact Modeling Framework', Paper Presented to the XII World Forestry Congress, September 21-28, Québec City, Canada.

Wittwer, G., S. McKirdy and R. Wilson (2005), 'Regional Economic Impacts of a Plant Disease Incursion Using a General Equilibrium Approach', Australian Journal of Agricultural and Resource Economics 49(1):75-89.

Zansler, M., T. Spreen and R. Muraro (2005), 'Florida's Citrus Canker Eradication Program (CCEP): Benefit-Cost Analysis’, EDIS document FE531, University of Florida, Gainesville.

The authors would like to thank two anonymous referees for their helpful suggestions, and Peter Donaghy of Queensland Department of Primary Industries and Fisheries for his encouragement and help in thinking through some of the issues discussed in this paper. Any errors, however, are attributable to the authors. 